\title{
TTR
}

Traduction, terminologie, re?daction

\section{Genres littéraires et traduction}

\section{Jean-Marc Gouanvic}

Volume 7, numéro 1, 1er semestre 1994

Genres littéraires et traduction

URI : https://id.erudit.org/iderudit/037166ar

DOI : https://doi.org/10.7202/037166ar

Aller au sommaire du numéro

Éditeur(s)

Association canadienne de traductologie

ISSN

0835-8443 (imprimé)

1708-2188 (numérique)

Découvrir la revue

Citer ce document

Gouanvic, J.-M. (1994). Genres littéraires et traduction. TTR, 7(1), 7-9.

https://doi.org/10.7202/037166ar

Tous droits réservés @ TTR: traduction, terminologie, rédaction — Les auteurs, d'utilisation que vous pouvez consulter en ligne.

https://apropos.erudit.org/fr/usagers/politique-dutilisation/ 


\section{GENRES LITTÉRAIRES \\ ET \\ TRADUCTION}

«Rien de ce qui se dit dans une société ne peut se dire identiquement partout. Ce qu'écrit un philosophe, un essayiste, il ne pourrait le "traduire" en vaudevilles ou en élégies!» (Marc Angenot, 1889. Un état du discours social, p. 95)

La critique littéraire classique tenait les genres pour des types fixes régis par des lois immuables. Cette conception $s^{\prime}$ est transmise bien au-delà du XVII siècle et, même si elle n'a plus guère de partisans déclarés aujourd'hui, elle semble parfois ressurgir à la faveur de l'engouement pour les structures, les formes ou les archétypes. Si le concept de genre est aujourd'hui l'objet d'un certain scepticisme, c'est sans doute parce qu'il a longtemps été confisqué par les formalismes et les académismes.

Ce numéro de TTR se situe aux antipodes d'une conception anhistorique ou transhistorique des genres. Les études ici publiées sont toutes - à leur échelle propre - traversées par une même exigence: penser ensemble la mise en œuvre des techniques expressives et leur signifiance sociohistorique.

Marc Angenot écrit dans l'ouvrage cité en exergue à la section Genres et discours: «La tradition littéraire connaît des genres, là où dans les secteurs politiques, scientifiques, publicistiques on parlera plutôt de discours. Les deux termes visent le même niveau systémique» (p. 95). Dans cette optique, parler de "genres littéraires», c'est nécessairement et dans le même temps se situer dans la perspective d'une socio-analyse des discours. $D^{\prime}$ ailleurs, dans sa phase préparatoire, ce numéro s'est appelé «la Traduction des genres et des discours (des genres \discours)». Les textes sélectionnés appartenant dans leur grande majorité au "discours littéraire», il n'y avait plus lieu de 
maintenir le couple synonymique et nous avons opté pour une seule forme, celle consacrée par la tradition.

Dans ce numéro, on observe une forte proportion des études (six) consacrées aux genres romanesques traduits du français vers l'anglais ou de l'anglais vers le français. Suivons la chronologie. L'étude de Joëlle Prungnaud rend compte $d^{\prime} u n$ cas remarquable de traduction pléthorique à la fin du XVIII siècle, celle du genre du "Gothic Novel» anglais en français. Un siècle plus tard, cette fois dans le sens France-Angleterre, Donald Bruce constate l'absence de traductions anglaises de la trilogie de Jacques Vingtras de Jules Vallès. L'auteur met cette absence sur le compte de l'exclusion du corpus lycéen dont Vallès est la victime et dont les causes sont à chercher dans les caractéristiques du texte anarchiste et du discours de la Commune. À la même époque, dans l'Angleterre victorienne, un auteur français ne manque pas d'être traduit, Émile Zola, représentant par excellence du roman naturaliste, mais - comme le montre Denise Merkle - non sans risques pour le traducteur et pour l'éditeur, même après (auto)censure des traductions. Jane Everett, quant à elle, étudie la traduction en français (1962) de l'essai littéraire de Virginia Woolf «How It Strikes a Contemporary» (1925). Dégageant les effets rhétoriques et discursifs de la traduction, elle montre que cette dernière est une réécriture qui change la fonction du texte de départ.

Passant à des corpus américains du $X X^{\mathbf{e}}$ siècle, les deux articles suivants abordent deux genres non canoniques, la science-fiction et la littérature pour la jeunesse. Jean-Marc Gouanvic trace à grands traits les déterminations sociologiques de la traduction et de l'importation de la "science-fiction" en France immédiatement après la Seconde Guerre mondiale. Claire le Brun analyse les caractéristiques institutionnelles (éditoriales et critiques) de la traduction de la littérature canadienne-anglaise pour la jeunesse publiée dans la collection «Les Deux Solitudes/Jeunesse» (éd. Pierre Tisseyre) entre 1980 et 1992.

Les deux essais qui closent le numéro relèvent de la traduction des textes sacrés et du théâtre. Eugene A. Nida 
présente une synthèse des problèmes sociolinguistiques que pose la traduction de textes religieux canoniques en relation notamment avec la force des traditions, l'oralité à préserver, le caractère "littéraire" de l'original et la diversité des variations textuelles. Enfin, Ekaterini Nikolarea présente un panorama des traductions, interprétations, imitations du modèle de la tragédie par excellence, CEdipe roi de Sophocle, dans les sociétés anglaise et française. L'auteure étudie les caractéristiques des manipulations que la pièce a subies en fonction des discours philosophiques, politiques et philologiques en vigueur dans les sociétés réceptrices.

Qu'il me soit permis, en terminant, d'annoncer aux lectrices et lecteurs de TTR que la revue vient d'obtenir l'aide financière du Fonds FCAR (Revues scientifiques) du Québec pour les trois années à venir. Cette reconnaissance rejaillit sur celles et ceux qui, depuis 1988, apportent leurs compétences à la Revue, sur les membres fidèles de l'Association canadienne de traductologie, dont elle est l'organe. Je pense tout particulièrement aux collaboratrices et aux collaborateurs de la rédaction, aux personnes qui nous soumettent les résultats de leurs recherches et à celles qui les évaluent en faisant des propositions pour que les textes publiés soient les meilleurs possibles. Cette subvention vient s'ajouter à celle que nous octroie le CRSH du Canada depuis le deuxième numéro, sans laquelle la revue ne serait pas ce qu'elle est aujourd'hui.

Jean-Marc Gouanvic 